\title{
Repetibilidade em características biométricas do fruto de macaúba
}

\author{
Repeatability in biometric characteristics of macaw palm fruit
}

\section{Candida Elisa Manfio ${ }^{\text {III* }}$ Sérgio Yoshimitsu Motoike ${ }^{\mathrm{I}}$ Carlos Eduardo Magalhães dos Santos ${ }^{\mathrm{II}}$ Leonardo Duarte Pimentel ${ }^{\mathrm{IV}}$ Vanessa de Queiroz $^{\mathrm{I}}$ Aurora Yoshiko Sato}

\section{RESUMO}

Estimativas do coeficiente de repetibilidade têm sido utilizadas no estudo de caracteres de várias espécies de palmeiras, auxiliando na definição do número e período adequado de avaliações dos genótipos para maior eficiência dos programas de melhoramento. Para macaúba, não há relatos de estudos dessa natureza. Nesse contexto, faz-se importante a determinação do coeficiente de repetibilidade das seguintes características biométricas dos frutos: peso do fruto, volume do fruto, diâmetro equatorial do fruto, peso da amêndoa, volume da amêndoa, diâmetro da amêndoa e espessura do endocarpo; e a determinação do número mínimo de avaliações para um eficiente processo de seleção e avaliação de subamostras de macaúba. O trabalho foi desenvolvido no Departamento de Fitotecnia da Universidade Federal de Viçosa, analisando-se 145 subamostras de macaúba, provenientes de coletas realizadas nos estados de Minas Gerais, São Paulo, Mato Grosso do Sul, Pará, Maranhão e Pernambuco. Houve diferença significativa para todas as características analisadas e observou-se concordância nas magnitudes dos coeficientes de repetibilidade de cada característica, obtidos pelos diferentes métodos. No entanto, os coeficientes de repetibilidade variam entre as oito caracteristicas, de 0,68 a 0,99, observados para a característica espessura do endocarpo e volume da amêndoa, respectivamente. As estimativas dos coeficientes de determinação obtidas a partir das 10 repetições para as oito características e pelos quatro métodos foram superiores a $95 \%$. A avaliação de quatro frutos é suficiente para compreensão das características estudadas das subamostras de macaúba com $90 \%$ de acurácia.

Palavras-chave: Acrocomia aculeata, medições, estimação.

\begin{abstract}
Estimates of repeatability coefficient have been used in character study of several species of palms, helping to define the number and appropriate period of assessment of genotypes to increase the efficiency of breeding programs. For macaw palm there are no reports of such studies. In this context it is important to determine the repeatability coefficient of the following biometric characteristics of fruits: fruit weight, fruit volume, equatorial diameter of the fruit, kernel weight, kernel volume, equatorial diameter of de kernel, and thickness of the endocarp, and the determination of the minimum number of ratings for an efficient selection process and evaluation of macaw palm subsamples. The study was conducted at the Department of Plant Science, Federal University of Viçosa, and 145 macaw palm subsamples were analyzed, from collections made in the states of Minas Gerais, São Paulo, Mato Grosso do Sul, Pará, Maranhão and Pernambuco. There were significant differences for all traits analyzed, and there was agreement on the magnitude of repeatability coefficients of each feature obtained by different methods. However, the repeatability coefficients ranging between eight characteristics, from 0.68 to 0.99 , and were observed for feature endocarp thickness and volume of kernel, respectively. The coefficient of determination obtained from 10 repetitions for the eight features and the four methods were superior to $95 \%$. The evaluation of four fruits is sufficient to assess the traits of macaw palm subsamples with $90 \%$ accuracy.
\end{abstract}

Key words: Acrocomia aculeata, measurement, estimation.

'Departamento de Fitotecnia, Universidade Federal de Viçosa (UFV), 36570-000, Viçosa, MG, Brasil. E-mail:cemanfio@yahoo.com.br *Autor para correspondência.

"Departamento de Estatística, UFV, Campus Rio Parnaíba, Rio Parnaíba, MG, Brasil.

IIIPrograma de Pós-graduação em Genética e Melhoramento, UFV, Viçosa, MG, Brasil.

IV Programa de Pós-graduação em Fitotecnia, UFV, Viçosa, MG, Brasil. 


\section{INTRODUÇÃO}

A macaúba (Acrocomia aculeata (Jacq.) Lodd. ex Martius) é uma palmeira nativa de regiões semi-áridas que apresenta alta produtividade. A espécie possui várias aplicações, principalmente no aproveitamento de seus frutos. Nesse sentido, a espécie tem se destacado, tendo em vista a propriedade oleaginosa dos frutos e sua elevada produtividade estimada (1500 a $5000 \mathrm{~kg}$ de óleo ha $\left.{ }^{-1}\right)$, sendo considerada também uma espécie potencial para a produção de biodiesel (TEIXEIRA, 2005).

A macaúba ainda é explorada de forma extrativista. Entretanto, para a exploração industrial, estudos apontam a necessidade de substituição dessa atividade por cultivos racionais, com cultivares e manejo adequados da espécie (WANDECK \& JUSTO, 1988).

As atividades orientadas para a coleta, identificação de características, funções biológicas, genes ou conjuntos gênicos desejáveis, em materiais não adaptados, semi-adaptados ou que não sofreram nenhuma forma de seleção, e sua mobilização para materiais potencialmente úteis a diferentes usuários da variabilidade genética, são atividades essenciais no começo dos programas de melhoramento.

Dentre os fatores que contribuem para o sucesso de um programa de melhoramento, conhecer o número de repetições (frutos) de cada material genético a ser coletado nas expedições é importante. Sendo a macaúba uma espécie perene, não domesticada, de longo ciclo de produção e devido ao elevado custo das expedições de coletas, conhecer o número de repetições (frutos) auxilia na programação das expedições de coletas, no sentido de otimizar o tempo e espaço necessários para coleta e transporte de materiais genéticos promissores que possam ser incorporados aos programas de melhoramento.

$\mathrm{Na}$ maioria das culturas perenes, os experimentos ocupam grandes áreas, muitas vezes instalados sem utilização de delineamento experimental adequado e, em geral, com longos prazos de execução (OLIVEIRA \& FERNANDES, 2001). Assim, tem-se procurado definir o número mínimo de repetições para avaliações de genótipos. Nos programas de melhoramento, procura-se reduzir ou eliminar o tempo gasto avaliando repetições além do necessário, bem como evitar a avaliação de um número reduzido que provocarão erros de estimação e falhas na identificação dos genótipos superiores (CARDOSO, 2006). O coeficiente de repetibilidade é uma alternativa para esses experimentos, por permitir tomar mais de uma medida no mesmo indivíduo, definindo o limite superior de repetibilidade e do grau de determinação
(VENCOVSKY, 1973; FALCONER, 1975; CRUZ et al., 2004)

Estimativas do coeficiente de repetibilidade têm sido utilizadas no estudo de caracteres de várias espécies de palmeiras, como coqueiro comum (SIQUEIRA, 1982), coqueiro híbrido (FARIAS NETO et al., 2003), açaizeiro (OLIVEIRA et al., 2000), pupunheira (FARIAS NETO et al., 2002), dendezeiro (CEDILLO et al., 2008; CHIA et al., 2009), tucumã (OLIVEIRA \& OLIVEIRA, 2008), bacaby (OLIVEIRA\& MOURA, 2008) e bacuri (SILVA et al., 2009), auxiliando na definição do número e período adequados de avaliação dos genótipos para maior eficiência dos programas de melhoramento. Para a espécie em estudo, não há relatos de pesquisas dessa natureza.

O conhecimento do coeficiente de repetibilidade permite, portanto, que a fase de avaliação seja executada com eficiência, mas com dispêndio mínimo de tempo e mão-de-obra (LOPES et al., 2001; COSTA, 2003).

A repetibilidade expressa a proporção da variância total, que é explicada pelas variações proporcionadas pelo genótipo e pelas alterações permanentes, atribuídas ao ambiente comum (ABEYWARDENA,1972; CRUZ et al., 2004). Valores altos da estimativa da repetibilidade do caráter indicam que é possível predizer o valor real do indivíduo com um número relativamente pequeno de medições (CRUZ et al., 2004), indicando que pouco ganho em acurácia haverá com o aumento do número de medições repetidas.

Nesse contexto, faz-se importante a determinação do coeficiente de repetibilidade de oito características biométricas dos frutos e a determinação do número mínimo de avaliações para um eficiente processo de seleção e avaliação de subamostras de macaúba.

\section{MATERIAL E MÉTODOS}

O trabalho foi desenvolvido no Departamento de Fitotecnia da Universidade Federal de Viçosa, analisando-se 145 subamostras de macaúba, provenientes de coletas realizadas nos estados de Minas Gerais, São Paulo, Mato Grosso do Sul, Pará, Maranhão e Pernambuco.

De cada subamostra, avaliaram-se dez frutos, aleatoriamente, e destes foram mensuradas as seguintes características: peso do fruto $(\mathrm{PF})(\mathrm{g})$ : cada fruto foi pesado separadamente em balança eletrônica de $0,01 \mathrm{~g}$ de precisão; volume do fruto (VF) (ml): em uma proveta volumétrica graduada contendo $200 \mathrm{ml}$ de água (Volume inicial), cada fruto foi introduzido, assim 
obteve-se um novo volume (Volume final) e, pela diferença do volume final pelo inicial, obteve-se o volume do fruto; diâmetro do fruto (DF) (mm): a medida equatorial de cada fruto foi aferida com paquímetro digital de 0,01 mm de precisão; peso da amêndoa (PA) (g): cada amêndoa foi pesada separadamente em balança eletrônica de $0,01 \mathrm{~g}$ de precisão; volume da amêndoa (VA) (ml): em uma proveta volumétrica graduada, contendo 50ml de água (Volume inicial), cada amêndoa foi introduzida, assim obteve-se um novo volume (Volume final) e, pela diferença do volume final pelo inicial, obteve-se o volume da amêndoa; diâmetro da amêndoa (DA) (mm): a medida equatorial de cada amêndoa foi aferida com paquímetro digital de $0,01 \mathrm{~mm}$ de precisão; espessura do endocarpo (EE) (mm): a medida foi aferida da porção do endocarpo aleatoriamente com paquímetro digital de $0,01 \mathrm{~mm}$ de precisão; índice de massa processável (IMP): (IMP = diâmetro equatorial do fruto $-2 \mathrm{x}$ espessura do endocarpo). $\mathrm{O}$ índice de massa processável é um índice estabelecido pelos autores para determinar quantitativamente a área processável do fruto, pois os frutos foram coletados no solo, sem conhecimento prévio da qualidade fisiológica dos frutos de cada subamostra.

As estimativas dos coeficientes de repetibilidade foram obtidas pelos métodos de análise de variância (ANOVA); componentes principais (CP), com base na matriz de correlações (CPC) e de covariâncias (CPCV); e análise estrutural (AE), com base na matriz de correlações.

No método de análise de variância, o coeficiente de repetibilidade é estimado por meio dos resultados da análise de variância, segundo o modelo:

$Y_{i j}=\mu+g_{i}+e_{i j}$ em que: $Y_{i j}$ : observação referente a i-ésima subamostra; $\mu$ : média geral; $g_{i}$ : efeito aleatório da i-ésima subamostra sob a influência do ambiente permanente $(i=1,2, \ldots, p)$; $e_{i j}$ : efeito do ambiente temporário associado à j-ésima medição na iésima subamostra $(\mathrm{j}=1,2, \ldots . \eta)$.

O coeficiente de repetibilidade foi dado por: $r=\hat{\rho}=\frac{\operatorname{Côv}\left(Y_{i j}, Y_{i j^{\prime}}\right)}{\sqrt{\hat{V}\left(Y_{i j}\right)} \hat{V}\left(Y_{i j^{\prime}}\right)}=\frac{\hat{\sigma}_{g}^{2}}{\hat{\sigma}_{Y}^{2}}=\frac{\hat{\sigma}_{g}^{2}}{\hat{\sigma}^{2}+\hat{\sigma}_{g}^{2}}$, em que: $Y_{i j}$ e $Y_{i j}$ são as diferentes medidas, realizadas num mesmo indivíduo.

Assim, foram estimados os resultados da análise de variância para cada variável descrita e estimados os componentes de variância associados aos efeitos genético e residual.

As estimativas dos coeficientes de repetibilidade foram obtidas pelo método dos componentes principais (ABEYWARDENA,1972), com base tanto na matriz de correlações como na matriz de covariâncias entre cada par de medições, avaliadas nas diferentes subamostras de macaúba.

Também foram obtidas as estimativas de repetibilidade pelo método da análise estrutural, com base na matriz de correlações entre as famílias em cada par de avaliação, conforme proposto por MANSOUR et al. (1981). De acordo com CRUZ et al. (2004), esse estimador é a média aritmética das correlações fenotípicas entre genótipos, considerando cada par de medições.

Uma vez estimado o coeficiente de repetibilidade (r), a estimativa do número de medições $\left(\eta_{0}\right)$ necessárias para se predizer o valor real dos indivíduos com o valor de determinação genotípica $\left(\mathrm{R}^{2}\right)$ desejado foi obtida pela expressão:

$$
\eta_{0}=\frac{\mathrm{R}^{2}(1-\hat{\mathrm{r}})}{\left(1-\mathrm{R}^{2}\right) \hat{\mathrm{r}}}
$$

O coeficiente de determinação genotípica $\left(\mathrm{R}^{2}\right)$, que representa a porcentagem de certeza da predição do valor real dos indivíduos selecionados com base em $n$ medições foi obtido pela equação:

$$
\mathrm{R}^{2}=\frac{\eta \mathrm{r}}{1+\mathrm{r}(\eta-1)}
$$

As estimativas foram obtidas através do procedimento repetibilidade do programa GENES (CRUZ, 2006a; CRUZ, 2006b).

\section{RESULTADOS E DISCUSSÃO}

De acordo com os resultados da análise de variância, verificaram-se diferenças significativas para todas as características analisadas (Tabela 1). Esses resultados evidenciam a variabilidade existente entre as subamostras estudadas, demonstrando que o componente de variância genético, confundido com os efeitos permanentes do ambiente, é significativo nesta população. As médias das características foram $32,12 \mathrm{~g}$ para $\mathrm{PF} ; 36,68 \mathrm{ml}$ para $\mathrm{VF}$; 39,86mm para DF; $1,69 \mathrm{~g}$ para $\mathrm{PA} ; 1,62 \mathrm{ml}$ para $\mathrm{VA} ; 16,55 \mathrm{~mm}$ para $\mathrm{DA}$; 4,75mm para EE; e 30,43 para IMP.

Houve concordância nas magnitudes dos coeficientes de repetibilidade de cada característica obtidas pelos diferentes métodos, conferindo-lhes maior confiabilidade (Tabela 2). No entanto, os coeficientes de repetibilidade variam entre as oito características (Tabela 2). Quando classificados pelos quatro métodos, a estimativa do coeficiente de repetibilidade (r) foi alta, conforme RESENDE (2002), que classifica como alta quando $r \geq 0,6$.

Os valores dos coeficientes de repetibilidade para as características variaram entre 0,68 e 0,99, observados para a característica espessura do 
Tabela 1 - Resumo da análise de variância para as características analisadas em 145 acessos de macaúba.

\begin{tabular}{lcrr}
\hline Características & QM acessos & QM resíduo & Média \\
\hline Peso Fruto & $3051,28^{*}$ & 28,20 & 32,12 \\
Volume Fruto & $2596,97^{*}$ & 10,77 & 36,68 \\
Diâmetro Fruto & $661,14^{*}$ & 2,48 & 39,86 \\
Peso Amêndoa & $4,71^{*}$ & 0,038 & 1,69 \\
Volume Amêndoa & $4,18^{*}$ & 0,0006 & 1,62 \\
Diâmetro Amêndoa & $96,35^{*}$ & 1,25 & 16,95 \\
Espessura Endocarpo & $7,05^{*}$ & 0,33 & 1,50 \\
IMP & $604,63^{*}$ & 3,83 & 4,74 \\
\hline
\end{tabular}

* Significativo em nível de $1 \%$ de probabilidade pelo teste $\mathrm{F}$.

endocarpo e volume da amêndoa, respectivamente, considerando os quatro métodos estudados.

A obtenção dos menores valores das estimativas de repetibilidade para a característica espessura do endocarpo estaria relacionada com a forma de obtenção dos dados da estrutura avaliada (endocarpo). A espessura do endocarpo é distribuída de forma heterogênea por seu perímetro e, em algumas subamostras, era encontrada mais de uma amêndoa por fruto, o que também acentuava heterogeneidade da espessura, pois não havia uma posição específica para a obtenção da medida, assim como foi para a característica diâmetro do fruto, em que a posição equatorial do fruto foi definida como padrão. A influência da variabilidade da espécie, da heterogeneidade do ambiente de coleta das subamostras pode ter colaborado na obtenção dos valores.

Não houve diferença para as estimativas dos coeficientes de repetibilidade das características obtidas pelos métodos estudados (Tabela 1). No entanto, trabalhos realizados com outras palmeiras, como pupunheira (FARIAS NETO et al., 2002), tucumã (OLIVEIRA \& OLIVEIRA, 2008), coqueiro híbrido (FARIAS NETO et al., 2003), dendezeiro do tipo dura (CEDILLO et al., 2008), caiaué e o dendezeiro (CHIA et al., 2009) e bacuri (SILVA et al., 2009) verificaram maior eficiência do método dos componentes principais da matriz de covariância (CPCV), na obtenção das estimativas do coeficiente de repetibilidade.

CHIA et al. (2009), avaliando os coeficientes de repetibilidade da produção de cachos de híbridos interespecíficos entre o caiaué e o dendezeiro, utilizando os mesmos métodos empregados neste trabalho, relataram que os menores coeficientes de repetibilidade foram obtidos pelo método da ANOVA, assim como OLIVEIRA \& MOURA (2008) para características do cacho de bacaby. Tal inferioridade, observada pelo método de ANOVA nos trabalhos relatados, é decorrente da variância genotípica, utilizada para estimar a repetibilidade nesta não ser somente de origem genética, uma vez que o componente de variância do ambiente permanente entre indivíduos permanece confundido com a variância genotípica (COSTA, 2003). O método dos componentes principais permite isolar o efeito da alternância, o que não ocorre na análise de variância, ficando esse componente incluído no erro experimental.

O método da análise estrutural proposto por MANSOUR et al. (1981), segundo CRUZ et al. (2004), apresenta diferenças conceituais em relação ao método dos componentes principais, assim, as estimativas obtidas pelos respectivos métodos tendem a ser próximas. Quando os valores das estimativas do coeficiente de repetibilidade são menores, a diferença entre os resultados obtidos pelos diferentes métodos aumenta, como ocorreu com a característica espessura do endocarpo.

As estimativas dos coeficientes de determinação, obtidas a partir das 10 repetições para as oito características e pelos quatro métodos, foram superiores a 95\% (Tabela 1), demonstrando que a avaliação das características pode ser realizada com alta confiabilidade. No entanto, deve-se buscar redução do número de avaliações para economia de recursos e tempo.

Assim, o número mínimo de frutos necessários para predizer o valor real dos genótipos, com $95 \%$ de coeficiente de determinação para PF, VF, DF, PA, VA, DA, EE e IMP será de 2, 1, 1, 2, 1, 2, 9 e 1, respectivamente, por qualquer um dos métodos estudados. Apenas para a variável espessura do endocarpo é necessário realizar a avaliação em mais de dois frutos para se obter coeficiente de determinação de $95 \%$.

Segundo CHIA et al. (2009), dentro dos níveis de precisão aceitáveis, deve-se buscar redução do período de avaliação e medições para economia de 
Tabela 2 - Estimativa dos coeficientes de repetibilidade $(\hat{r})$, coeficientes de determinação $\left(\mathrm{R}^{2}\right)$ e do número de medições calculados, utilizando os métodos de análise de variância (ANOVA), dos componentes principais baseado na matriz de correlação (CPC), dos componentes principais baseado na matriz de covariância (CPCV) e da análise estrutural baseado na matriz de correlação (AE) para as características peso do fruto (PF), volume do fruto (VF), diâmetro do fruto (DF), peso da amêndoa (PA), volume da amêndoa (VA), diâmetro da amêndoa (DA) e espessura do endocarpo (EE), em 10 frutos, em 145 subamostras de macaúba.

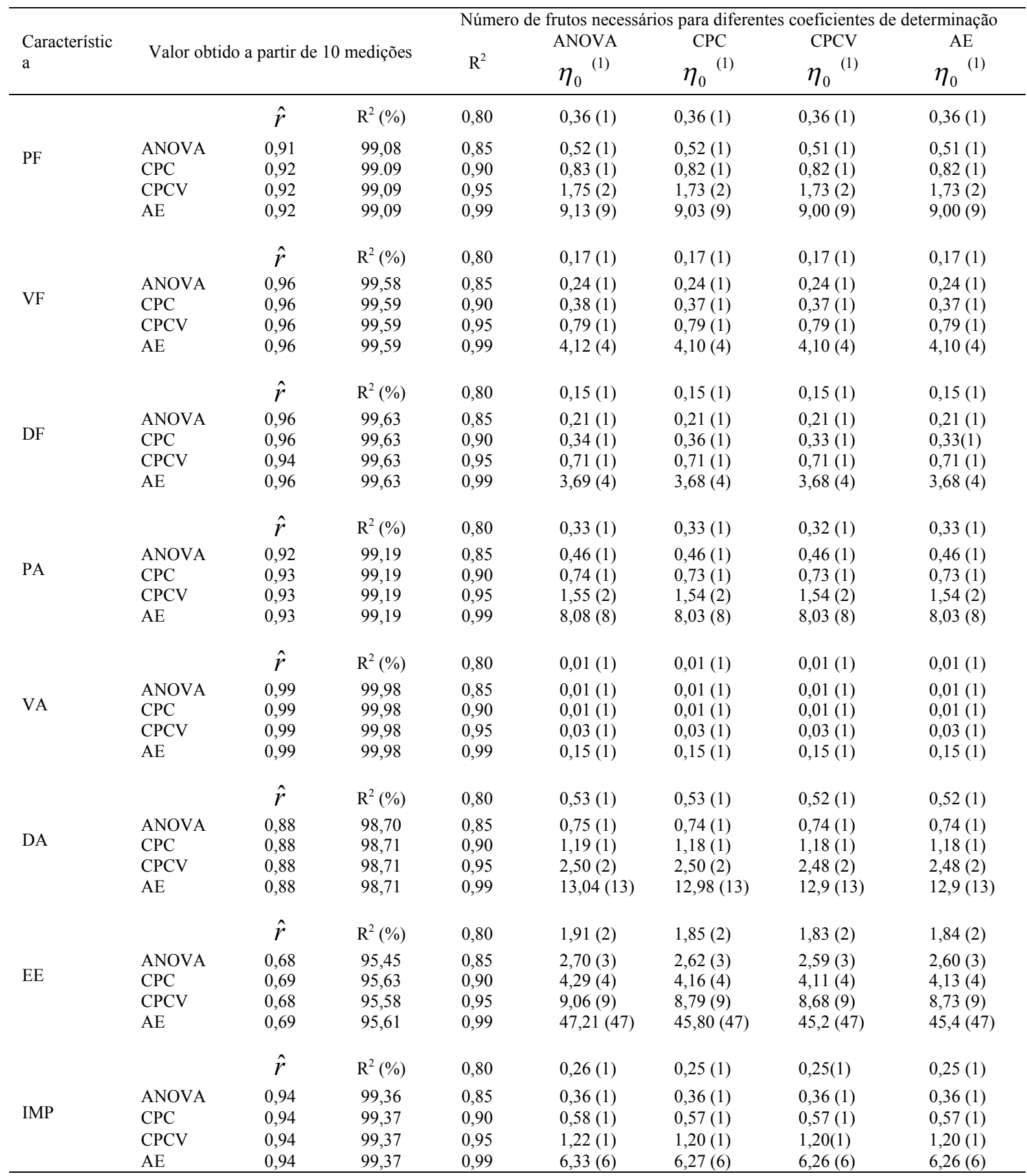

(1) Número aproximado (número calculado). 
recursos e tempo. CEDILLO et al. (2008) e COSTA(2003)

utilizaram coeficientes de determinação entre 80 e $90 \%$ em seus estudos com dendê e manga, respectivamente. Neste estudo, com coeficiente de determinação de $90 \%$ é possível reduzir o número de avaliações das características PF, VF, DF, PA, VA, DA, EE e IMP para $1,1,1,1,1,1,4$ e 1 frutos, respectivamente. Assim, essas estimativas indicam que com quatro frutos é possível realizar a avaliação das características com um bom coeficiente de determinação.

Com o estudo realizado, verificou-se que a redução de dez para quatro frutos não torna o processo de avaliação menos eficiente.

\section{CONCLUSÃO}

Não houve diferença entre as estimativas dos coeficientes de repetibilidade obtido pelos métodos estudados.

Quatro frutos são suficientes para avaliação das características estudadas das subamostras de macaúba com coeficiente de determinação de $90 \%$.

\section{AGRADECIMENTOS}

À Fundação de Amparo à Pesquisa de Minas Gerais (FAPEMIG) e ao Conselho Nacional de Desenvolvimento Científico e Tecnológico (CNPQ), pelo apoio financeiro.

\section{REFERÊNCIAS}

ABEYWARDENA, V. An application of principal component analysis in genetics. Journal of genetics, v.61, p.27-51, 1972 .

CARDOSO, A.I.I. Número mínimo de colheitas em pepino híbrido estimado por meio do coeficiente de repetibilidade. Bragantia, v.65, p.591-595, 2006. Disponível em: <http:// www.scielo.br/scielo.php? script $=$ sci_arttext\&pid $=$ S0006$87052006000400009>$. Acesso em: 25 jan. 2010. doi:10.1590/ s0006-87052006000400009.

CEDILLO, D.S.O. et al. Correlation and repeatability in progenies of African oil palm. Acta Scientiarum Agronomy, v.30, p.197201, 2008. Disponível em: <http://periodicos.uem.br/ojs/ index.php/ActaSciAgron/article/view/1728/1016>. Acesso em: 25 jan. 2010. doi: 10.4025/actasciagron.v30i2.1728.

CHIA, G.S. et al. Repetibilidade da produção de cachos de híbridos interespecíficos entre o caiaué e o dendezeiro. Acta Amazonica, v.39, p.249-254, 2009. Disponível em: <http:// www.scielo.br/scielo.php? script $=$ sci_arttext\&pid $=$ S00445967200900020000>. Acesso em: 25 jan. 2010. doi:10.1590/ s0044-5967009000200001.

COSTA, J.G. Estimativas de repetibilidade de alguns caracteres de produção em mangueira. Ciência Rural, v.33, p.263-266, 2003. Disponível em: <http://www.scielo.br/scielo.php?pid=S0103$84782003000200013 \&$ script=sci_arttext $>$. Acesso em: 25 jan. 2010. doi:10.1590/s0103-8478003000200013.
CRUZ, C.D. Programa Genes - Análise multivariada e simulação. Viçosa: UFV, 2006a. 175p.

CRUZ, C.D. Programa Genes - Estatística experimental e matrizes. Viçosa: UFV, 2006b. 285p.

CRUZ, C.D. et al. Modelos biométricos aplicados ao melhoramento genético. 3.ed. Viçosa: UFV, 2004. 480p.

FALCONER, D.S. Introduction to quantitative genetics. London: Longman, 1975. 365p.

FARIAS NETO, J.T. et al. Coeficientes de repetibilidade genética de caracteres em pupunheira. Revista Brasileira de Fruticultura, v.24, p.731-733, 2002. Disponível em: $<$ http:/ /www.scielo.br/scielo.php?script=sci_arttext\&pid=S010029452002000300042>. Acesso em: 25 jan. 2010. doi: 10.1590/ s0100-29452002000300042.

FARIAS NETO, J.T. et al. Estimativas dos coeficientes de repetibilidade para produção de frutos de albúmem sólido em coqueiro hibrido. Pesquisa Agropecuária Brasileira, v.38, p.1237-1241, 2003. Disponível em: $<$ http://www.scielo.br/scielo.php?pid=S0100204X2003001000014\&script=sci_arttext $>$. Acesso em: 25 jan. 2010. doi: 10.1590/s0100-204x2003001000014.

LOPES, R. et al. Repetibilidade de características do fruto de aceroleira. Pesquisa Agropecuária Brasileira, v.36, p.507-513, 2001. Disponível em: <http://www.scielo.br/scielo.php?pid=S0100204X2001000300015\&script $=$ sci_arttext $>$. Acesso em: 25 jan. 2010. doi: $10.1590 / \mathrm{s} 0100-204 \times 2001000300015$.

MANSOUR, R. et al. Estimators of repeatability. Theorical Applied Genetics, v.60, p.151-156, 1981.

MOTTA, P.E. et al. Ocorrência de macaúba em Minas Gerais: relação com atributos climáticos, pedológicos e vegetacionais. Pesquisa Agropecuária Brasileira, v.37, p.1023-1031, 2002. Disponível $\mathrm{em}:<\mathrm{http}: / / \mathrm{www} . \mathbf{s c i e l o}$.br/scielo.php?script=sci_arttext\&pid=S0100204X2002000700017>. Acesso em: 25 jan. 2010. doi: 10.1590/ s0100-204x2002000700017.

OLIVEIRA, M.S.P. et al. Correlações fenotípicas entre caracteres vegetativos e de produção de frutos em açaizeiro. Revista Brasileira de Fruticultura, v.22, p.1-5, 2000. Disponível em: $<$ http://www.scielo.br/scieloOrg/php/reflinks.php?refpid=S01002945200100030003400006\&pid>. Acesso em: 25 jan. 2010. doi:10.1590/s0100-2945200100030003400006.

OLIVEIRA, M.S.P.; FERNANDES, G.L.C. Repetibilidade de caracteres do cacho de açaizeiro na condiçoes de Belém-PA. Revista Brasileira de Fruticultura, v.23, p.613-616, 2001. Disponível em: <http://www.scielo.br/scielo.php?pid=S0100$29452001000300034 \&$ script $=$ sci_arttext\&tlng $=$ en $>$. Acesso em: 25 jan. 2010 . doi: 10.1590/s0100-29452001000300034.

OLIVEIRA, M.S.P.; MOURA, E F. Estimativas de repetibilidade para caracteres de cacho de Bacaby (Oenocapus mapora). In: CONGRESSO BRASILEIRO DE FRUTICULTURA, 20., 2008. Vitória, ES. Anais... Vitória, 2008. Disponível em: <http:// 200.137.78.15/cd_XXCBF/paginas/MelhorGenBioestatistica/ 20080627_222253.pdf>. Acesso em: 25 jan. 2010.

OLIVEIRA, N.P.; OLIVEIRA, M.S.P. Repetibilidade para caracteres de cacho de tumumãzeiro. In: CONGRESSO BRASILEIRO DE FRUTICULTURA, 20., 2008. Vitória, ES. 
Anais... Vitória, 2008. Disponível em: $<$ http://200.137.78.15/ cd_XXCBF/paginas/MelhorGenBioestatistica/ 20080628_174922.pdf>. Acesso em: 25 jan. 2010.

RESENDE, M.D.V. de. Genética biométrica e estatística: no melhoramento de plantas perenes. Brasília: Embrapa Informação Tecnológica, 2002. 975p.

SILVA, R.G. et al. Repetibilidade e correlação fenotípicas de caracteres do fruto de bacuri no estado do Maranhão. Acta Scientiarum Agronomy, v.31, p.587-591, 2009. Disponível em: <http://periodicos.uem.br/ojs/index.php/ActaSciAgron/ article/viewArticle/723>. Acesso em: 25 jan. 2010. doi: 10.4025/actasciagron.v31i4.723.
SIQUEIRA, E.R. Coeficiente da repetibilidade de produção de frutos de coqueiro comum. Pesquisa Brasileira Agropecuária, v.17, p.572-574, 1982.

TEIXEIRA, L.C. Potencialidades de oleaginosas para produção de biodiesel. Informe Agropecuário, v.26, p.18-27, 2005.

VENCOVSKY, R. Princípios de genética quantitativa. Piracicaba: ESALQ, 1973. 97p.

WANDECK, F.A.; JUSTO, P.G. A macaúba, fonte energética e insumo industrial: sua significação econômica no Brasil. In: SIMPOSIO SOBRE O CERRADO, SAVANAS, 1988, Brasília, DF. Anais... Planaltina: EMBRAPA, CPAC, 1988. p.541-577. 